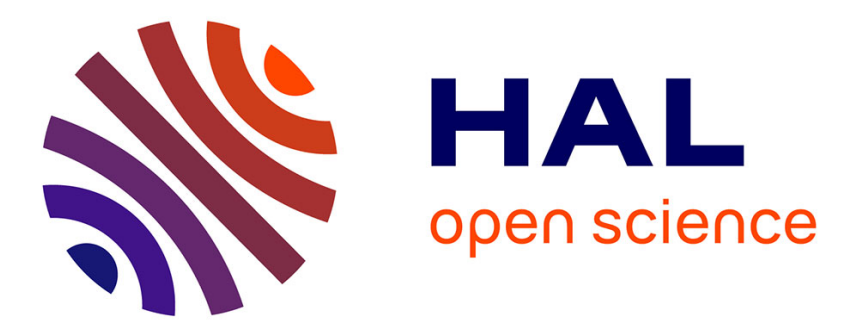

\title{
Crystallographic investigation of transient states by time-resolved techniques using synchrotron radiation \\ H.D. Bartunik
}

\section{To cite this version:}

H.D. Bartunik. Crystallographic investigation of transient states by time-resolved techniques using synchrotron radiation. Revue de Physique Appliquée, 1984, 19 (9), pp.671-675. 10.1051/rphysap:01984001909067100 . jpa-00245236

\section{HAL Id: jpa-00245236 https://hal.science/jpa-00245236}

Submitted on 1 Jan 1984

HAL is a multi-disciplinary open access archive for the deposit and dissemination of scientific research documents, whether they are published or not. The documents may come from teaching and research institutions in France or abroad, or from public or private research centers.
L'archive ouverte pluridisciplinaire HAL, est destinée au dépôt et à la diffusion de documents scientifiques de niveau recherche, publiés ou non, émanant des établissements d'enseignement et de recherche français ou étrangers, des laboratoires publics ou privés. 


\title{
Crystallographic investigation of transient states by time-resolved techniques using synchrotron radiation
}

\author{
H. D. Bartunik \\ EMBL c/o DESY, Notkestrasse 85, 2000 Hamburg 52, F.R.G.
}

\begin{abstract}
Résumé. - On peut étudier la structure de molécules dans des états excités de courte durée de vie ou dans des états transitoires, au moyen de la diffraction des rayons $X$ sur une échelle de temps supérieure à 100 ps grâce à la forte intensité et au caractère pulsé du rayonnement synchrotron. On décrit les techniques expérimentales, qui peuvent utiliser les techniques cryogéniques, et les résultats d'étude d'états excités par laser avec une résolution temporelle comprise entre 10 ns et $500 \mu \mathrm{s}$.
\end{abstract}

\begin{abstract}
The three-dimensional structure of short-lived excited or transient states in molecules may be investigated by means of time-resolved X-ray diffraction on time scales $>100$ ps using the high intensity and pulsed time structure of synchrotron radiation. The experimental techniques, which may involve crystal cooling to low temperatures, and results of first applications to studies of laser-excited states with a time resolution between $10 \mathrm{~ns}$ and $500 \mu \mathrm{s}$ are described.
\end{abstract}

\section{Introduction.}

Knowledge of the three-dimiensional structure of molecules in excited or transient states is of potential importance for a number of problems in different fields of research. Examples in molecular biology are intermediate states in reaction pathways like the binding of substrate molecules to enzymes or the binding of ligands to active centres in proteins.

Such investigations are mainly complicated by the in general short lifetimes of such states. For example, ligand rebinding to heme proteins involves time scales between picoseconds and milliseconds at room temperature (RT); reorientational motion of individual amino acid residues in protein molecules happen at RT on a $10-100$ ns time scale.

A number of intramolecular biological processes may be slowed down by applying crystal cooling techniques; such processes, in particular irreversible reactions, may then be investigated by quasi-stationary diffraction techniques.

If a reaction can be cycled, time-resolved investigation may be feasible by making use of the unique properties of synchrotron radiation (SR), primarily of its high spectral brilliance and pulsed time structure.

Time-resolved crystallographic techniques using SR have been developed during the last few years and applied in studies of transient states in biological $[1,2]$ and non-biological structures [3-5] on time scales between $10^{-9} \mathrm{~s}$ and $10^{-3} \mathrm{~s}$. These techniques and the results of first applications are described and discussed in the following.

\section{Biological applications on time scales $>10^{-4} \mathrm{~s}$.}

The functioning of proteins is in many cases known to involve transient changes in the molecular structure. Examples are domain motions occurring in a number of enzymes during catalytic interaction with substrate molecules, collective opening-and-closing movements of side chains providing access for ligand molecules to the interior of heme proteins, and intermediate states of membrane proteins undergoing a photocycle.

The lifetime of transient states in protein molecules can be as short as $10^{-12} \mathrm{~s}$ at RT; in many cases, however, it is in the range of $10^{-9} \mathrm{~s}$ to $10^{-3} \mathrm{~s}$. Nanosecond time-resolved protein crystallography is in theory feasible (see below). At the present moment, however, collection of a sufficiently complete timeresolved data set for structural analysis of transient states in protein molecules is within reach only for time scales $>10^{-4} \mathrm{~s}$.

If a suitable cryosolvent $[6,7]$ can be found, protein crystals may be cooled to low temperatures for prolonging the lifetime of such states. The technique of protein structure analysis at low temperatures down to $100 \mathrm{~K}$ to very high Bragg resolution (1.6 A) has first been applied to an investigation of flexibility in trypsinogen [8], an inactive precursor of the digestive 
enzyme trypsin. Further low-temperature studies are in progress; they include in particular investigation of the structure of short-lived trypsin-substrate complexes by quasi-stationary techniques using SR.

High-resolution studies at temperatures $>100 \mathrm{~K}$ are feasible with a crystal cooling device [9] which has been used in a number of SR applications in protein crystallography, in particular also in the abovementioned studies of the trypsin-trypsinogen system. It consists essentially of a double chamber, mounted on a standard goniometer head, which is cooled with $\mathrm{N}_{2}$ gas. A temperature control system including a (Si diode) sensor, a magnetic valve (optional), a heater and commercial electronics (WISSEL, Starnberg, F.R.G.) provide temperature stability to better than $0.5^{\circ} \mathrm{C}$; higher stability may be achieved if needed. The double chamber design reduces temperature gradients near the sample to a minimum; thus, problems like condensation of solvent near the crystal within the capillary tube or even dissolving of the crystal are avoided. The thin Mylar foils covering the cold chamber are transparent both for X-rays and optical light; the device may therefore also be used in crystallographic studies of optically excited structures.

\section{Millisecond time-resolved protein crystallography.}

The feasibility of time-resolved protein crystallography on a submillisecond time scale has been demonstrated by a first application to a study of $\mathrm{CO}$ ligand rebinding to carbonmonoxy-myoglobin (MbCO) following photolysis by a laser pulse [1, 2]. The experiment was carried out on the doublefocussing tunable instrument X11 at DORIS ; figure 1 shows schematically the experimental set-up. The time course in the Bragg intensities of (in total ca. 30) reflections was measured with a real-time data acquisition system based on a linear gas detector (A. Gabriel, C. Boulin). The data were accumulated in a selfincrementing CAMAC memory which was paged into 100 time frames of $500 \mu$ s each. The timing circuit triggered a laser pulse (Rhodamin 6G dye laser pumped by a $\mathrm{Xe}^{*} \mathrm{Cl}$ excimer laser; $\lambda=590 \mathrm{~nm}$; pulse energy $200 \mu \mathrm{J}$; pulse length $15 \mathrm{~ns}$ ). The laser light was focussed onto a small $\mathrm{MbCO}$ crystal with platelike dimensions of $200 \times 200 \times 20 \mu \mathrm{m}$. A constant flow of solvent through the capillary tube reduced heating of the crystal by the laser pulse to an estimated increase in temperature by a few ${ }^{\circ} \mathrm{C}$.

Figures 1, 2 show the time course in a number of reflection intensities before and after triggering the laser pulse photolysing the $\mathrm{CO}$ ligand. The data were accumulated in the paged memory over a few hundred repeated cycles. For several reflections, intensity changes have been observed immediately after the laser excitation; they show exponential relaxation (Fig. 2) to the initial value. The relaxation time of a few ms agrees well with the result of time-resolved optical transmission measurements on $\mathrm{MbCO}$ sin-

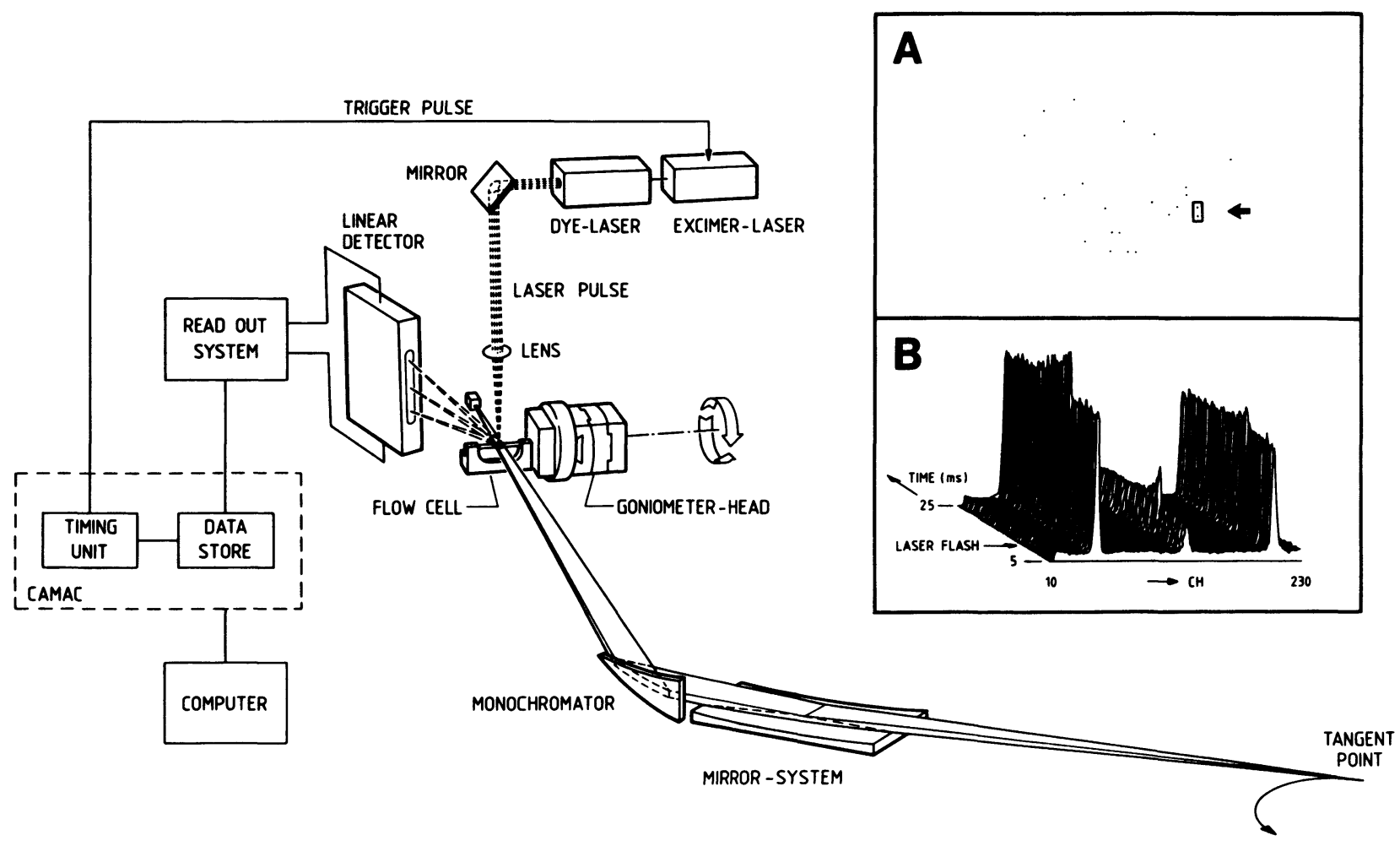

Fig. 1. - Experimental set-up of the double-focussing tunable instrument X11 at DORIS for millisecond time-resolved crystallographic data collection for $\mathrm{MbCO}$ following photodissociation of the ligand by a laser pulse [2]. (B) shows the time course, measured with a resolution of $500 \mu \mathrm{s}$, in three simultaneously recorded reflection intensities. 

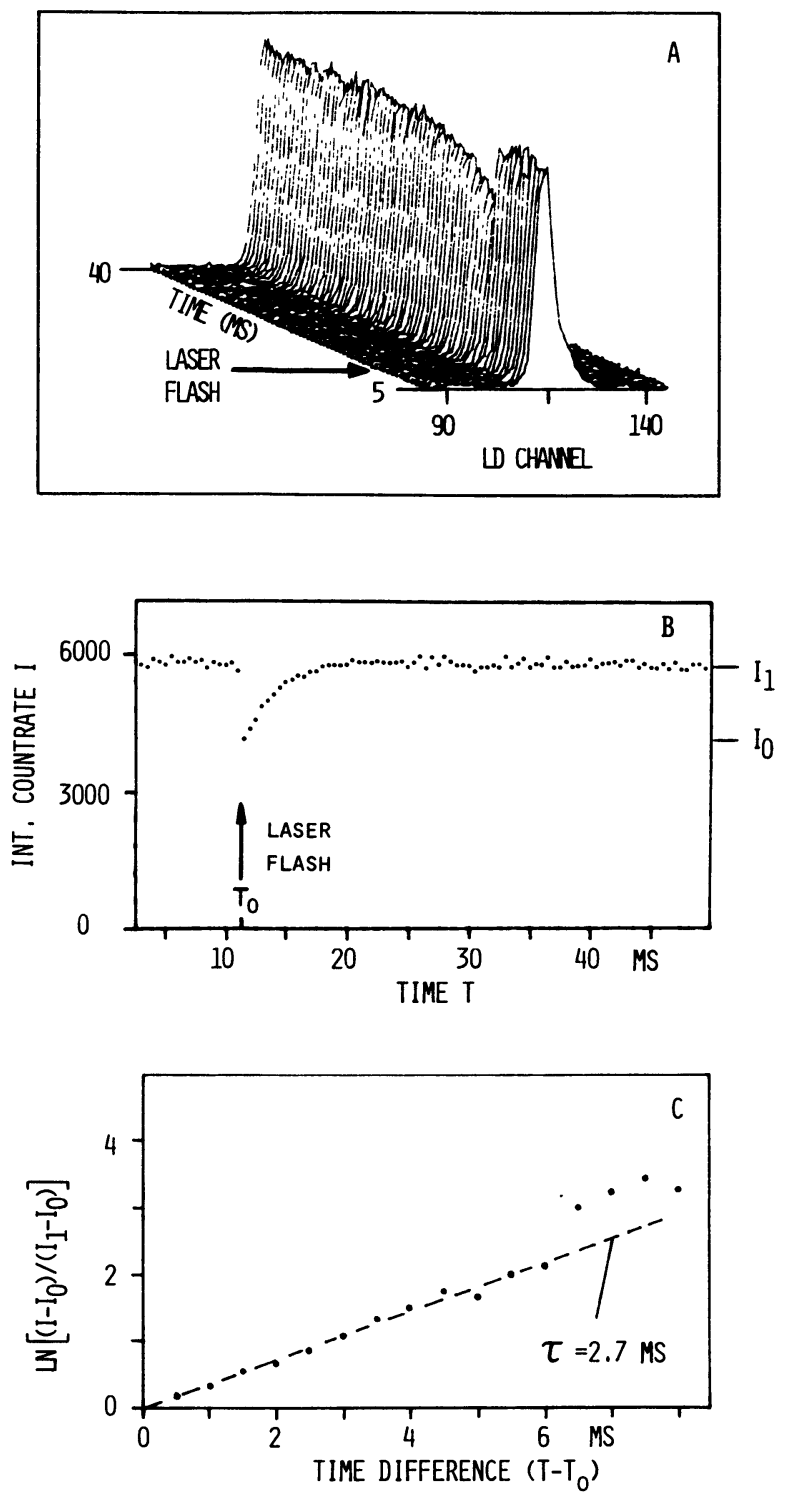

Fig. 2. - Exponential relaxation of laser induced change in the X-ray diffraction intensity of a $\mathrm{MbCO}$ reflection [2].

gle crystals (Fig. 3) using the same laser configuration as for the X-ray diffraction studies, and with previous results of optical studies on $\mathrm{MbCO}$ in solution by Frauenfelder and coworkers [10]. The results of the time-resolved SR experiments may on the basis of Frauenfelder's investigations be interpreted in terms of (practically) instantaneous photodissociation of the CO ligand by the laser pulse and subsequent rebinding of the ligand to the protein. The relatively long time scale of rebinding may be explained on the basis of a model [10] which involves, at RT, diffusion of the debound ligand out of the heme pocket into the solvent surrounding the protein. The observed changes in the Bragg intensities reflect the change in the relative populations of $\mathrm{MbCO}$ and deoxy-Mb.

The MbCO photolysis study is continued with the aim of collecting a complete time-resolved data set to high resolution at low temperatures. At $100 \mathrm{~K}$, ligand rebinding happens on a time scale of $100 \mu \mathrm{s}$. At the same time, reorientational motion of side chains is slowed down so that is should be possible to determine, on the basis of time-resolved diffraction data, the transient structure of the protein in the geminate state following photodissociation.

The further work will be carried out using an area detector (MWPC) with a hardware data reduction system (DACOM, [11]). DACOM is based on the fact that the positions of the reflections in the pattern may be predicted. This allows to use a combination of a masked dual-port memory and a second selfincrementing memory for discriminating between events occurring within reflection (or background) areas on the detector and other events to be neglected; integration over reflection (or background) intensities for a given crystal orientation is done by hardware. Accumulation of intensities in separate time frames is achieved by paging the second memory.

\section{Nanosecond time-resolved crystallography.}

Very short time scales $>100$ ps may be reached by making use of the pulsed time structure of SR. At DORIS, the width in time of individual bunches is of the order of $100 \mathrm{ps}$; the interval between subsequent SR pulses in single-bunch mode is $960 \mathrm{~ns}$. The master clock of the ring provides a means for triggering stimulation of the sample by an external source like, e.g., a laser in phase with the SR pulses. Variation of the time delay between stimulating pulse and the probing SR pulse allows stroboscopic diffraction measurements with a time resolution between 100 ps and $960 \mathrm{~ns}$.

Such a stroboscopic technique has been used in a recent study of a short-live ( $\tau=18.6 \mathrm{~ns})$ excited $4 \mathrm{f}^{0} 5 \mathrm{~d}^{1}$ state of $\mathrm{Ce}^{3+}$ in monocrystalline $\mathrm{CeP}_{5} \mathrm{O}_{14}$ [5]. Previous optical measurements provided evidence for a decrease in the $\mathrm{Ce}^{3+}$ ionic radius in the excited $4 f^{0} 5 d^{1}$ state as compared to the $4 f^{1} 5 d^{0}$ ground state. It was postulated on the basis of the known structure of $\mathrm{CeP}_{5} \mathrm{O}_{14}$ (monoclinic spacegroup $\mathrm{P} 2_{1} / \mathrm{c}$ ) that such a change in ionic radius should cause a change in the cell dimensions, mainly in the $b$-axis. Such a change has in fact been observed in the rocking curve of the (020) reflection measured with a time resolution of $15 \mathrm{~ns}$ before, during and after excitation of the $\mathrm{Ce}^{3+}$ $4 \mathrm{f}^{0} 5 \mathrm{~d}^{1}$ state at $307 \mathrm{~nm}$ by a $\mathrm{Xe}{ }^{*} \mathrm{Cl}$ excimer laser. The choice of this reflection was based on the results of a previous millisecond time-resolved diffraction study of (the isomorphous structure) $\mathrm{CeTbP}_{5} \mathrm{O}_{14}$ [3]. The results of this study showed that heating of the lattice by the laser pulse induced a phase transition involving a change in the monoclinic angle, $\beta$; the rocking curve of the $(020)$ reflection should not be affected by such a change in $\beta$.

The nanosecond time-resolved diffraction experiment has been carried out on the double-focussing 


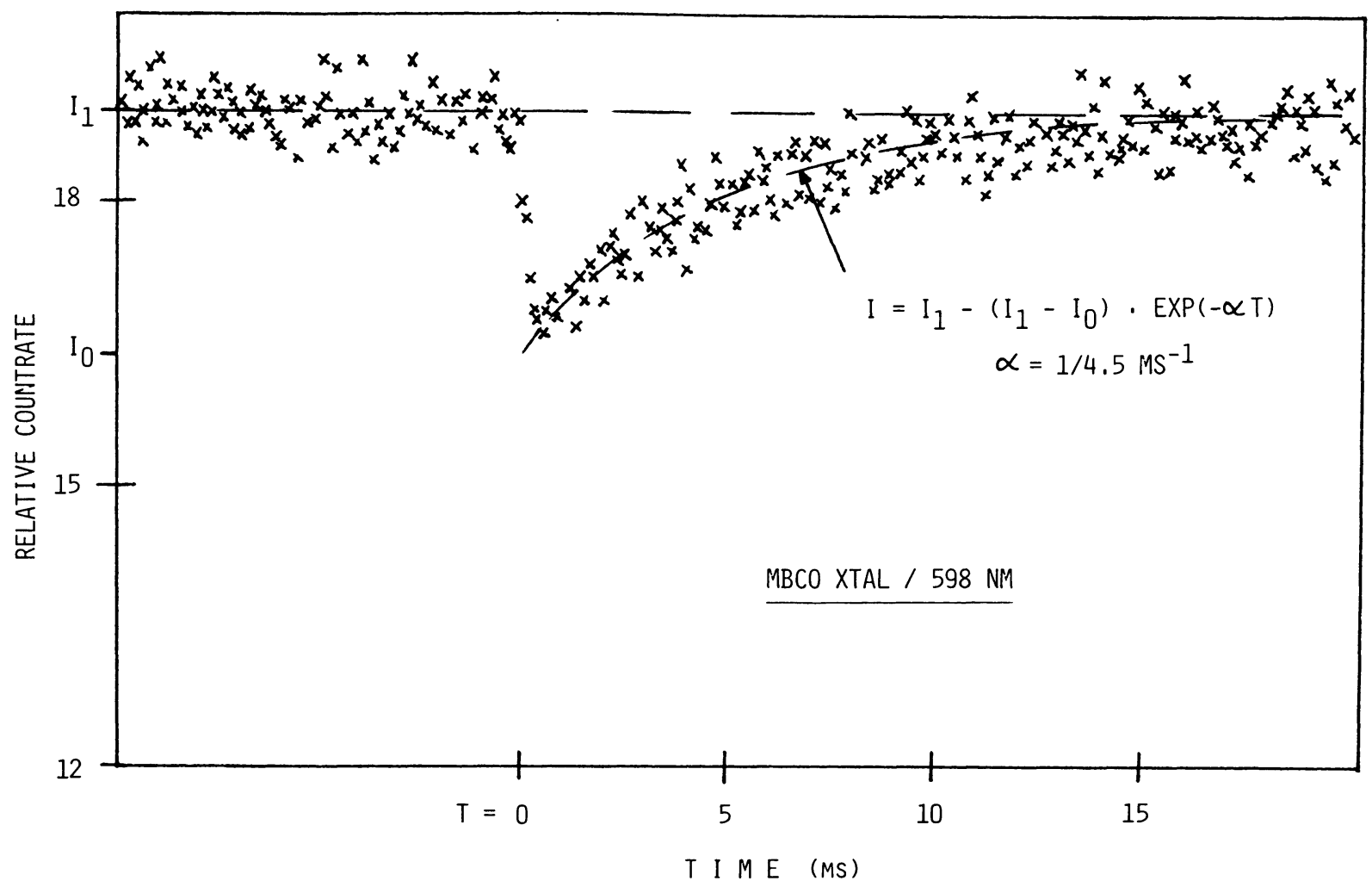

Fig. 3. - Time-resolved measurement of laser induced change in the optical transmission at $590 \mathrm{~nm}$ through a $\mathrm{MbCO}$ crystal.

instrument X31 at DORIS/HASYLAB [12]. Details of the experimental techniques are described elsewhere [5].

Nanosecond time-resolved techniques are also of interest for biological applications, e.g., for investigation of transient structural changes in heme proteins following fast ligand rebinding, or of the threedimensional structure of short-lived excited states in membrane proteins which undergo a photocycle. Such applications ideally require area detectors with an intrinsic time resolution below $1 \mu \mathrm{s}$, which corresponds to the time interval between subsequent SR pulses in single-bunch mode; such systems are still in development. Use of a single counter may, however, allow to collect a partial data set which could provide a basis for an interpretation based on structural model calculations.

\section{Conclusions.}

The high intensity of SR, its tunability and pulsed time structure provide the basis for crystallographic investigation of short-lived excited or transient states.

The use of cooling techniques for prolonging the lifetime of such states may in many cases allow to analyse their three-dimensional structure by quasistationary techniques (on a time scale of minutes to hours); this possibility is of particular importance for the case of reactions which may not be cycled, as for example most enzyme-substrate reactions. Low-tem- perature techniques for high-resolution studies at temperatures $>100 \mathrm{~K}$ in structural biology have recently become available and have already been used routinely. Suitable cryostats for high-resolution protein crystallography at very low temperatures down to $4 \mathrm{~K}$ are in development ; such very low temperatures are of potential interest mainly for studies of intramolecular dynamics.

Cycling of reactions allows three-dimensional structure analysis of excited or transient states on a time scale of $100 \mathrm{ps}$ to $1 \mu \mathrm{s}$ with stroboscopic diffraction techniques using, at present, single counters. On a longer time scale $>1 \mu \mathrm{s}$, the whole time course may be followed by accumulating data into many time frames, and linear and area detectors may be used for simultaneous measurement of many reflections from macromolecular structures. In both time resolution ranges, first successful experiments in biology, solid state physics and materials science have demonstrated the feasibility and provided first results. It is expected that methods of time-resolved crystallography will during the next few years be applied to many more problems in a number of fields.

These methods, in particular in the nanosecond time range, may very substantially profit from the even higher SR intensity which will become available through the installation of insertion devices (wigglers, undulators) in existing storage rings and the construction of new high-intensity SR sources which are being planned. 


\section{References}

[1] Bartunik, H. D., Jerzembek, E., Pruss, D. and Huber, G., Biophys. Struct. Mech. 7 (1981) 249.

[2] BartuniK, H. D., Nucl. Instrum. Methods 208 (1983) 523.

[3] Pruss, D., Huber, G., Danielmeyer, H. G. and Bartunik, H. D., Acta Crystallogr. A, Suppl. Ser. 37 (1981) C-306.

[4] Larson, B. C., White, C. W., Noggle, T. S. and Mills, D., Phys. Rev. Lett. 48 (1982) 337.

[5] Pruss, D., Huber, G., Danielmeyer, H. G. and BARTUNIK, H. D., in preparation (1984).

[6] Petsko, G. A., J. Mol. Biol. 96 (1975) 381.

[7] Douzou, P., Hui Bon Hoa, G. and Petsko, G. A., J. Mol. Biol. 96 (1975) 367.
[8] Walter, J., Steigemann, W., Singh, T. P., Bartunik, H. D., Bode, W. and Huber, R., Acta Crystallogr. B 38 (1982) 1462.

[9] Bartunik, H. D. and Schubert, P., J. Appl. Crystallogr. 15 (1982) 227.

[10] Austin, R. H., Beeson, K. W., Eisenstein, L., FrauenFELDER, H. and Gunsalus, I. C., Biochemistry 14 (1975) 5355.

[11] Bartunik, H. D. and Boulin, C., in Structural Biological Applications of $X$-ray Absorption, Scattering and Diffraction, H. D. Bartunik and B. Chance, eds. (Academic Press, NY) 1984, in press.

[12] Bartunik, H. D., Bartels, K. S. and Allibon, J., in preparation (1984). 